\title{
Official thumbs down
}

\section{Washington}

To no one's surprise, the panel set up by the Department of Energy (DoE) to assess cold fusion has sent in a negative report. An interim opinion released earlier this year by the panel, a group of 23 electrochemists, nuclear physicists and materials scientists assembled by the DoE's Energy Research Advisory Board (ERAB), acknowledged that there were some odd and unexplained results in the air but recommended against any special support of cold fusion experiments (see Nature 340, 174; 1989). The panel's final report expresses the same verdict a little more forcefully, but the ERAB meeting at which the report was approved and passed on to DoE Secretary James Watkins did reveal some differences of opinion on the significance and credibility of the handful of 'positive' results still extant.

Summarizing the final report, John Huizenga, a professor of physics and chemistry at the University of Rochester and one of the ERAB panel's co-chairmen, showed little patience with those who have continued to claim that there is at least a little evidence for cold fusion of the heat-producing variety. None of the calorimetry, he declared, was of good enough quality to be believed, and in any case calorimetry alone would never prove the case. Huizenga was particularly unhappy with those who argued that because the claimed excess heat could not possibly be of conventional origin it had to be nuclear, despite measurements which showed unequivocally that no fusion products were being generated.

Discounting the calorimetry, the only anomalous claim still needing an explanation was that of Kevin Wolf of Texas A\&M University, who repeatedly finds tritium in his electrochemical cells. But new evidence from Wolf, discussed at last week's ERAB meeting, argues against a nuclear origin. Tritium produced by deuterium fusion comes with an energy of $1 \mathrm{MeV}$ and is accompanied by a $3 \mathrm{MeV}$ proton. Energetic tritons will react with deuterium, either in the palladium electrode or in the electrolyte, producing secondary neutrons, and the protons can excite some palladium nuclei, which give up a $500 \mathrm{keV}$ photon on de-excitation. In his latest experiments, Wolf has searched for both these secondary signatures and found nothing. His tritium, therefore, must have some kind of low-energy origin.

Nevertheless, Wolf has also searched minutely for sources of contamination, and found nothing there either.

This puzzling result, together with a few calorimetric measurements that he found somewhat convincing, led recent Nobel prizewinner Norman Ramsey of Harvard University (see Nature 341, 556; 1989), the panel's other co-chairman, to conclude that the case against cold fusion was not closed. At his insistence, a preamble was added to the report's conclusions which notes that "it is not possible to state categorically that all the claims for cold fusion have been convincingly either proved or disproved".

Huizenga felt that this preamble "weakened" the report, but Ramsey and some others felt that the report would undermine itself if it looked too dogmatic in its dismissal of the evidence.

On the subject of the low-level fusion process espoused by Steven Jones of Brigham Young University, the panel agreed that more work was needed, although here again Huizenga, noting that EAST GERMAN EXODUS

\section{Problems remain for those who stay}

\section{Munich}

EAST German researchers now living in West Germany are happy but sceptical about the events in East Germany that culminated in last week's opening of the Berlin Wall. No one disputes that the opening of the borders is a momentous and irreversible step, but many doubt that the effects of 40 years of Communist repression can be wiped away overnight: the repressive system is more deeply entrenched in East Germany than, for example, in Hungary, which has also enacted radical reforms this year.

Under the old system, said a number of researchers, Party members and other desirables were given the opportunity to travel abroad, publish in foreign journals and make progress in their scientific careers, but those who lacked an ideological pedigree were cut off from the West and forced to engage in political activities against their

West Germany continued to welcome all those who came over from East Germany on Friday, even though the capacity of the refugee camps had nearly been exhausted. Most of the refugees who had arrived before the Wall came down seemed to be in practical, not academic, professions, although an accurate tally was made impossible by the large numbers. But organizations involved in helping East German researchers and academics get on their feet in West Germany said they would need much more money to continue the process.

Uta Paffhausen of the Education Ministry reported that the number of applications for "adjustment aid", given to help East German emigrants find academic posts, had risen to about 50 in the past two months. The grants are provided by the ministry as well as by the Otto Benecke Foundation. The ministry also administers a programme to provide fellowships for refugees whose training is unsuitable for working in West Germany. The two programmes were to provide a total of DM 24 million (\$13 million) in 1990 when the refugee total was still expected to be about 60,000 . But by 10 November, the number had topped 500,000 , including 200,000 East Germans and another 300,000 ethnic Germans from Poland and the Soviet Union. Photo: The wall near Checkpoint Charlie last Friday, seen from the East (AP). all the claims were of marginal statistical significance, seemed less impressed than some of the other panel members that there really was a phenomenon to be explained.

Although he showed some sympathy for those still making claims for cold fusion, Ramsey also said that if the results on which the claims were based came from his laboratory, he would keep quiet and do more experiments until he understood better what was going on. The ERAB report accepts that people are free to submit experimental proposals to granting agencies in the hope of obtaining support for cold fusion experiments, but recommends that only if experiments are likely to yield useful results - closed-cell calorimetry with simultaneous nuclear monitoring is deemed essential - should support be given. David Lindley

will. The pessimism brought on by such obstructions caused these people, like so many others, to escape.

Those who tried to leave by legal means found that as soon as they submitted visa applications, they were forbidden to work in their laboratories. One said he was reinstated only after an invitation to a scientific meeting from a prominent West German research institution, in which he now has a job. But the only way to find out about such opportunities is to have personal and professional contacts, said another.

Researchers said after the recent lifting of travel restrictions that they were waiting to see if the changes are large enough to encourage development of a system based on personal achievement and not privilege. Even so, East German research laboratories will still lack the money to order basic supplies, let alone to subscribe to foreign journals.

Steven Dickman 